Multiaccess, Mobility and Teletraffic in Wireless Communications: Volume 4 


\section{Multiaccess, Mobility and Teletraffic in Wireless Communications: Volume 4}

Edited by

\section{Ezio Biglieri}

Politecnico di Torino, Italy

\section{Luigi Fratta}

Politecnico di Milano, Italy

and

Bijan Jabbari

George Mason University, U.S.A. 
A C.I.P. Catalogue record for this book is available from the Library of Congress.

ISBN 978-1-4419-5109-0 ISBN 978-1-4757-5920-4 (eBook)

DOI 10.1007/978-1-4757-5920-4

Printed on acid-free paper
All Rights Reserved
(C) 1999 Springer Science+Business Media New York
Originally published by Kluwer Academic Publishers, Boston in 1999
Softcover reprint of the hardcover 1st edition 1999
No part of the material protected by this copyright notice may be reproduced or utilized in any form or by any means, electronic or mechanical, including photocopying, recording or by any information storage and retrieval system, without written permission from the copyright owner. 


\section{Table of Contents}

Preface

New Mobile Telephony in the Organisational Communication

O. Galibert, B. Salgues, O. Epinette

System Overload and System Utilization - Myths and Realities

D. McRae, O. Panfilov, R. Saxon, R. Seetharamaiah.

Experimental GSM Test Bed for Adaptive Array Antenna System

G. Bucci, A. Colamonico, M. Donati, M. Politi, A. Picciriello.

High Speed Optical Data Link for Smart Antenna Mobile Radio System

C. Savazzi.

Spectrally Efficient Turbo Codes with Full Antenna Diversity

H.-J. Su, E. Geraniotis

A Novel DAB Technique Using Code Combining, Packet Combining, and Iterative Decoding (Turbo Code)

B.K. Yi, S.G. Kim, R. Pickholtz.

Multiple Access Using Periodic Clock Changes Through Slow Fading Multipath Channel

A. Hayar, B. Lacaze, D. Roviras

On the Impact of Signal-Level-Based Power Control on Terminal Battery Duration

M. Chiani, A. Conti, R. Verdone.

Generalized Quasi-Walsh PN Sequences and Their Applications in Robust CDMA Communication Systems

C. Giardina, A.N. Rudrapatna.

Rate Processor Sharing: A Robust Technique for Scheduling Data

Transmissions in CDMA Wireless Networks

K. Kumaran, P. Whiting

The Initial Synchronisation Procedure in UMTS W-CDMA

S. Kourtis.

Iterative MMSE Multiuser Detection for Coded CDMA Channels with Multisensor Transmitter and Receiver Arrays

J. Thomas, E. Geraniotis 
Trading-off Capture Against Packet Separation for Throughput and Energy Efficiency in Random Access Systems

W. Luo, A. Ephremides

The Concept of PARPS - Packet and Resource Plan Scheduling

M. Eriksson, H. Säterberg.

A Distributed Channel Allocation Method for Self-Organising Base Stations in a Wireless ATM Unlicensed System

G.F. Marias, L. Merakos

Resource Allocation for Integrated Voice/WWW Traffic in UMTS/TDD Systems

C. Mihailescu, X. Lagrange, Ph. Godlewski

An Extended Error Control Technique for Wireless ATM Channel

Z. Ilic, S. Pilipovic, M. Kos.

Universal Platform for High-Speed Wireless OFDM Link Evaluation

K. Verdijck

Seamless Multimedia Service for Third Generation Mobile Radio Networks M. Ferracioli, R. Verdone.

Cell Assignability on Random Paths in CDMA Networks

A. Leu, B. Jabbari

Key Issues in Handover Design and Multi-Layer Cellular System Design

M. Lohi, D. Weerakoon, A.H. Aghvami

Configuration Data Verification and Design Techniques for Mobile Network Architecture Nodes

D. D'Aurelio, M. Nespoli, M. Travaglini, M. Areddu, R. Arizio, C. Eynard, G.

Gentile.

Investigation of Alternative ARQ Schemes for a Wireless ATM Network

D. Skyrianoglou, L. Merakos

Fair Sharing of MAC under TCP in Wireless Ad-hoc Networks

K. Tang, M. Gerla.

Fair Queueing Scheduler for IEEE 802.11 Based Wireless Multimedia Networks R.S. Ranasinghe, D. Everitt, L.L.H. Andrew 241

Performance Analysis of a Cellular Slotted CDMA System with Imperfect Power Control over a Rayleigh Fading Channel

J.M. Romero Jerez, M. Ruiz García, A. Díaz Estrella 253 
Efficiency Comparison Between CDMA and PRMA-HS in Low Earth Orbit Mobile Satellite Systems

A. Abrardo, G. Giambene, D. Sennati ........................................................... 263

Multiple Access Interference in Multi-beam CDMA-based LEO Satellite Systems

H. Fu, G. Bi, K. Arichandran.................................................................... 273

Capacity Considerations for Wireless MIMO Channels

F. Boixadera Espax, J. J. Boutros

Determination of Critical Transmission Range in Ad-Hoc Networks

M. Sanchez, P. Manzoni, Z.J. Haas

293

An Adaptive QoS Representation and Resource Allocation Scheme for Multimedia and Wireless ATM Networks Using Genetic Algorithms

M.R. Sherif, I.W. Habib, M. Naghshineh, P. Kermani. 


\section{Preface}

The unrelenting growth of wireless communications continues to raise new research and development problems that require unprecedented interactions among communication engineers. In particular, specialists in transmission and specialists in networks must often cross each other's boundaries. This is especially true for CDMA, an access technique that is being widely accepted as a system solution for next-generation mobile cellular systems, but it extends to other system aspects as well. Major challenges lie ahead, from the design of physical and radio access to network architecture, resource management, mobility management, and capacity and performance aspects.

Several of these aspects are addressed in this volume, the fourth in the edited series on Multiaccess, Mobility and Teletraffic for Wireless Communications. It contains papers selected from MMT99, the fifth Workshop held on these topics in October 1999 in Venezia, Italy. The focus of this workshop series is on identifying, presenting, and discussing the theoretical and implementation issues critical to the design of wireless communication networks. More specifically, these issues are examined from the viewpoint of the impact each one of them can have on the others.

Specific emphasis is given to the evolutionary trends of universal wireless access and software radio. Performance improvements achieved by spectrally efficient codes and smart antennas in experimental GSM testbeds are presented. Several contributions address critical issues regarding multimedia services for Third-Generation Mobile Radio Networks ranging from high rate data transmission with CDMA technology to resource allocation for integrated Voice/WWW traffic. Network architectures are proposed for efficient mobility management in an Internet based mobile wireless network and for route optimization for hand-off connections in wireless ATM. Finally, the increasing interest for global personal communications is reflected in a few papers addressing the efficiency of mobility and multiple access in Low Earth Orbit Mobile Satellite Systems.

Our hope is that the material presented in this volume will help stimulate many ideas for future research.

Ezio Biglieri

Luigi Fratta

Bijan Jabbari 
We wish to extend our sincere gratitude to Dr. Federico Tosco and Dr. Andrew Viterbi, the Workshop Co-chairs. We thank Donatella Bertolotti for the support in the process of collection and selection of the papers. We are also grateful to Franco Bertoldi and the Staff of the Istituto Internazionale delle Comunicazioni (IIC) for support in the organization of the workshop.

The MMT 99 Technical Program Committee:

Tony Acampora

Hamid Aghvami

Victor Bahl

Yeheskel Bar-Ness

Kalyan Basu

Thorsten Benkner

Ezio Biglieri (Technical Cochair)

Giuseppe Caire

Justin Chuang

Giovanni Colombo

John Daigle

Anthony Ephremides

Luigi Fratta (Technical Cochair)

Woldemar Fuhrmann

Davide Grillo

Franco Grimaldi

Zygmunt Haas

Ibrahim Habib

Stephen Hanly

Bijan Jabbari

Ravi Jain

Faroog Khan

Ryuji Kohno

Xavier Lagrange

Kin Leung

Rudolf Mathar

P. Takis Mathiopoulos

Mahmoud Naghshineh

Decio Ongaro

Kaveh Pahlavan

Roberto Palazzi

Greg Pollini

Pietro Porzio Giusto

Guy Pujolle

Christopher Rose

Michael Schopp

Dirk Slock

Elvino Sousa

Angelo Tognoni

Sergio Verdu

Branimir Vojcic

Branka Vucetic

Phil Whiting

Patricia Wirth

Tak-Sing Yum

Djamal Zeghlache

Valerio Zingarelli 